\title{
3. el PREÁMBULO de LA CONSTITUCIÓN DE 1845
}

MARÍA ANUNCIACIÓN TOMÁS FONT DE MORA 


\section{SUMARIO}

Los Preámbulos de 1837 y de 1845.-El PRincipio de soberanía NACIONAL. SU SUPRESIÓN.-LA SOBERANIA CONJUNTA Y LA FÓRMULA DE PROMULGACIÓN.-LOS ANTIGUOS FUEROS Y LIBERTADES.-CONSTITUCIÓN INTERNA Y CARTA CONSTITUCIONAL.-CONSTITUCIÓN REFORMADA O CONSTITUCIÓN NUEVA. - 1. La tesis de la reforma.-2. Una constitución nueva. 


\title{
3. EL PREÁMBULO DE LA CONSTITUCIÓN DE 1845
}

\author{
POR \\ MARÍA ANUNCIACIÓN TOMÁS FONT DE MORA
}

\section{LOS PREÁMBULOS DE 1837 Y 1845}

La reforma constitucional de $1844-45$ se justificó, entre otros extremos, por la necesidad de modificar enteramente la redacción y sentido del Preámbulo.

De manera inicial conviene señalar que los que, en una u otra posición, participaron en la discusión de la reforma, tenían conciencia de la importancia del Preámbulo, en el que se determina la autoridad y legitimidad de quien la acuerda: «...En el Preámbulo —decía DÍAZ CID- se fijan las bases del edificio; es el cimiento de donde arranca la piedra angular que marca todos los frentes que ha de tener la cuadratura que ha de ocupar...." ". "El Preámbulo - señalaba ISLA- es la parte principal del proyecto que discutimos: en él vamos a fijar el principio de que partamos; él va a ser el cimiento de la obra que levantemos; si este cimiento se sienta sobre un terreno firme, la otra subsistirá; si le sentamos en falso sobre arena movediza, al primer viento vendrá al suelo..." ${ }^{2}$.

La significación y el valor político que tenía la nueva redacción del Preámbulo aconseja recordar el texto del mismo en cada una de las Constituciones.

El Preámbulo de la de 1837 decía así: "Doña Isabel II, por la gracia de Dios y de la Constitución de la Monarquía española, Reina de las Españas y en su Real nombre y durante su menor edad, la Reina Viuda su

DSC, 12 noviembre 1844, pág. 409.

2 DSC, 13 noviembre 1844, pág. 420. 
Madre Doña María Cristina de Borbón, Gobernadora del Reino, a todos los que la presente vieren y rindieren, sabed: Que las Cortes generales han decretado y sancionado y Nos de conformidad aceptado lo siguiente: Siendo la voluntad de la Nación revisar, en uso de su soberanía, la Constitución política promulgada en Cádiz el 19 de Marzo de 1812, las Cortes Generales, congregadas a este fin, decretan y sancionan la siguiente Constitución de la Monarquía española».

El Preámbulo de la de 1845 decía de esta manera: «Doña Isabel II, por la gracia de Dios y de la Constitución de la Monarquía española, Reina de las Españas, a todos los que la presente vieren y entendieren, sabed: Que siendo nuestra voluntad y la de las Cortes del Reino regularizar y poner en consonancia con las necesidades actuales del Estado los antiguos fueros y libertades de estos Reinos y la intervención que sus Cortes han tenido en todos los tiempos en los negocios graves de la Monarquía, modificando al efecto la Constitución promulgada en 18 de Junio de 1837, hemos venido en unión y de acuerdo con las Cortes actualmente reunidas, en decretar y sancionar la siguiente Constitución de la Monarquía española».

La lectura y comparación de los dos textos permite formular algunas precisiones iniciales y esenciales.

La Constitución del 37 descansaba sobre el principio de la soberanía nacional. La Comisión de las Constituyentes que la preparó, redactó el conciso, pero solemne proemio que - según su propia expresión-se reducía "a consignar el gran principio de la soberanía nacional, que ha sido, que es y que siempre será el único origen legítimo de todas las Constituciones de los pueblos...". Ciertamente, algunos de éstos lo habian recibido de un poder que pretendía hablar en nombre de Dios, para disfrazar sacrilegamente una tirania: el poder absoluto así establecido podía oprimir por más o menos tiempo a las Naciones; "pero jamás despojarlas de aquel derecho inherente a su existencia, indispensable a su conservación, el de constituirse del modo que mejor les convenga...". El principio habia sido desconocido en muchas épocas y regiones, sin que ello le restase validez e importancia; pero, precisamente por ello, resultaba obligado consignarlo con toda solemnidad y convenía que se proclamase en el proemio de la Constitución: «...Así se evitan —concluía el dictamen- las falsas y perjudiciales interpretaciones a que podría dar lugar si formase por sí sólo un artículo. Fijando el principio al tiempo mismo que de él se hace la debida aplicación, no debe entenderse que pueda ser mal entendido.... ${ }^{3}$.

3 El texto del dictamen en Sevilla Andrés: Constituciones $y$ otras Leyes $y$ Proyectos Políticos de España, Madrid ,1969, tomo I, pág. 317 y ss. Sobre la colocación del principio en el Preámbulo, véase Colomer Viadel, A: El sistema político de la 
Los redactores de la nueva Constitución rechazaban de plano el principio y las consecuencias que el proemio de la del 37 había querido extraer del mismo. Los Ministros, en la exposición preliminar al proyecto de reforma, después de algunas consideraciones iniciales relativas a la conveniencia de aquélla, decían a la Reina: «...Han creido, ante todas las cosas, que debía cambiarse el Preámbulo de la Constitución, juzgando inoportuno, si es que no peligroso, el principio que en él se enunciaba, del cual podrian tal vez deducirse consecuencias poco conformes al decoro y firmeza del Trono y al acuerdo que debe subsistir entre los Poderes del Estado. Lejos, pues, de acudir a principios abstractos más o menos vagos respecto del origen de las Constituciones, vuestros Secretarios del Despacho han juzgado preferible anunciar el hecho, a saber: que en la Constitución que va a regir a España están de acuerdo la Corona y las Cortes deseando concurrir unidas a acomodar los antiguos fueros y libertades de la Nación a su estado y necesidades actuales dando a las Cortes la intervención que en todos tiempos han tenido en la resolución de los asuntos graves de la Monarquía.... " ${ }^{4}$. El párrafo suponia, de una parte, una glosa sucinta del Preámbulo; de otra, apuntaba los argumentos que en la discusión parlamentaria se desarrollarían en oposición al principio de la soberanía nacional.

Este principio, en su sentido propio, supone tener presente, al menos, dos consideraciones distintas. De una parte, el Rey no es ya el origen y centro de todos los poderes; los poderes tienen residencia primitiva y central sólo en la nación; en especial, el poder constituyente reside en la nación misma; el Rey no puede, pues, hacer ni reformar la Constitución; como todos los órganos de la nación, no es un órgano constituyente, sino un órgano constituido.De otra, el principio exige que la nación sea siempre dueña de cambiar libremente su régimen constitucional; se opone a que la revisión pueda depender de la voluntad del monarca, bien sea en cuanto a su iniciación o proposición, bien en cuanto a su perfección; si la revisión estuviese subordinada al consentimiento del Rey, nos encontraríamos, de algún modo, ante una confiscación de la soberanía nacional, ya que nada podría afectarlo sin su consentimiento.

Constitución española de 1837, Madrid, 1980, pág. 98. SÁnChez Agesta señala atinadamente el valor político que el principio confería a la Constitución del 37: Historia del Constitucionalismo español, ed.1964, pág. 228.

4 El texto de la Exposición en loc. cit. La tesis habia sido desarrollada más ampliamente en la exposición preliminar al Estatuto Real, cuyo texto puede verse en Sevilla Andrés, D.: Constituciones..., pág. 257. En la época del Estatuto, Martínez de la Rosa había denunciado ya el supuesto carácter y vago anárquico del principio: véase en este sentido, Tomás VIllarroya, J.: El Sistema político del Estatuto Real, Madrid, 1968. 
La doctrina progresista de la época y la prensa del mismo signo de la etapa que se está estudiando recogian esencialmente las consideraciones expuestas. JOAQUÍN M. a LÓPEZ, en 1840, había señalado ya: "...Para las leyes fundamentales no se necesita sanción. Formada una Constitución por los representantes del pueblo, el Rey la acepta y la jura y para nada hace falta el testimonio de su consentimiento consignado en el acto..." ${ }^{5}$. La prensa progresista, en el mes de octubre del 44 , subrayó de manera más directa e intencionada la doctrina. El Eco del Comercio del 4 escribía: “...La nación española es arbitra de constituirse a su placer. Las leyes políticas son un mandato con respecto a la Corona; y a la Corona le compete únicamente la aceptación. La aceptación regia es el principio de sus obligaciones y derechos. Hasta ridículo es pensar que el trono intervenga en la formación de las leyes fundamentales; porque dándoles o negándoles su sanción se restablecería el falso derecho divino de los reyes, destruyendo la soberanía realmente divina de los pueblos...". En una línea de pensamiento parecida, El Espectador del 24 del mismo mes, refiriéndose a la Constitución de 1837, precisaba: "...Esta Carta que es la expresión de la nación, porque es la voluntad de los más, a cuyo voto se someten todos en la sociedad, esta Carta, en ningún caso puede ser válidamente modificada por nadie sino por la nación misma, por el mismo poder que la formó...".

\section{EL PRINCIPIO DE LA SOBERANIA NACIONAL. SU SUPRESIÓN}

Los defensores de la reforma no admitían el principio $y$, sobre todo, no podian aceptar las consecuencias. De ahí que, de una parte, lo suprimiesen; de otra que lo sustituyesen por el de la soberanía conjunta de la Corona y de las Cortes.

La supresión del principio despertó, casi aisladamente, la oposición de POSADA, quien juzgaba que debía conservarse por motivos varios: "Era un principio filosóficamente verdadero y prácticamente cierto"; se encontraba establecido "directa o indirectamente en todas las Constituciones de Europan; en la tradición histórica española, junto al principio monárquico, se encontraba el de la nacionalidad, "entidad que, como las Cortes y la Monarquía, ha atravesado catorce siglos y ha atravesado más: ha atravesado mil siglos, puesto que su origen se pierde en la noche de los tiempos"; finalmente, en nuestra historia reciente, cuando la dinastía

5 Joaquin M. - López: op. cit., Lección 5. 
se rindió a la invasión extranjera, la nación hizo "lo que hace un gran pueblo: acordarse de que era independiente, libre, soberano, darse una Constitución; pelear por ella seis años y salvar el trono y las leyes fundamentales..." ${ }^{6}$. Sin embargo, frente a tales razonamientos, los promotores de la reforma propusieron al menos tres argumentos dispares, pero todos ellos coincidentes en la conveniencia y aun en la necesidad de suprimir el principio.

Primero.-El carácter abstracto del principio. La Exposición preliminar redactada por el Gobierno - según ya se ha visto- denunciaba esta supuesta condición del mismo. El Ministro de la Gobernación, PIDAL, insistió en la denuncia: se trataba de "un principio abstracto, puramente teórico y de escuela, absurdo...": principio "que muchisimos hombres niegan, otros se burlan de él y ningún partido político ha podido aplicar...". El principio, verdadero o falso, puramente especulativo, podría servir acaso para una nación joven que tuviese que dar fuerza $y$ prestigio a una dinastía salida de la nada; pero no a una nación antigua, como España, con una dinastía que ocupaba la preminencia de los Estados de Europa: "...¿A qué apelar —concluía- a ese principio abstracto, inaplicable, que es la mofa y el desprecio de muchos hombres?..." ?. En este lugar no procede un examen detenido del principio: basta tener presentes las consecuencias políticas ya analizadas, derivadas del mismo, para advertir que aquél podía ser objeto de aprecio o menosprecio; pero no podía reputarse como meramente doctrinal y de escuela.

Segundo.-La dudosa o, al menos, la variable utilidad del principio. En este punto, MARTÍNEZ DE LA ROSA advertía que pudo ser muy útil en las Cortes y Constitución de 1812, para oponerse a la usurpación extranjera y cuando los Reyes españoles habian abdicado la Corona; pero en la de 1837 no tenía ese sentido y suponía, en cambio, un insulto para la Corona: «...No es un principio abstracto de la soberanía, explicado en una Academia o en una aula; es el sello de la revolución de la Granja y es menester borrarlo..." ${ }^{8}$. El Ministro de Hacienda, MON, en una línea de argumentación parecida, advertía que el principio se habia aplicado en España con resultados sorprendentes: "...Hay un hecho notabilísimo en España - decía- que es de mucho peso y es que cuando no ha estado consignado se ha llevado a efecto y cuando lo ha estado no ha servido ni producido los fines que se deseaban. Por ejemplo, en el año 1808, no estaba consignado este principio en ninguna Carta Consti-

DSC, 31 octubre 1844, págs. 169-70.

DSC, 30 octubre 1844, pág. 149.

DSC, 11 noviembre 1844, pág. 391. 
tucional y se levantó el país en masa ejerciendo la soberanía nacional; por el contrario, en el año 1823, estaba consignado en la Constitución de aquella época y los 100.000 soldados franceses hicieron lo que quisieron.... ${ }^{9}$.

Tercero.- El principio suponía una incitación o pretexto para la rebelión. MARTÍNEZ DE LA ROSA pedía que no se olvidase nuestra historia y nuestra revolución: "...¿Cuántas veces - preguntaba- no hemos visto al menor motín, al menor levantamiento, los que se convocaban y reunían en el lodazal de una plaza o de un café, hablar a nombre del pueblo soberano, y llevar a sus miras a los hombres dóciles que se persuadian de que representaban y defendían sus intereses? Es preciso no arrojar esos principios vagos y perniciosos; es preciso que la nación sepa cuáles son sus derechos legítimos; pero deben decírsele también cuáles son sus deberes, que éste es el modo de hablar al pueblo, no corromperle y precipitarle..." ${ }^{10}$. La argumentación quizás requiera una matización: el principio de la soberanía nacional no era, por sí sólo, revolucionario; pero, bajo la vigencia de la Constitución del 37 , la casi totalidad de los motines, de los pronunciamientos en tono mayor o menor, de los movimientos subversivos, habían levantado la bandera de aquel principio.

El partido progresista, ausente de las Cortes, no pudo manifestar, en sede parlamentaria, su protesta por la supresión del principio; pero sus órganos de expresión recordaron la vigencia del mismo y la afrenta que a la nación se hacía. El Espectador un día escribia: «...En España, los reyes y sus dinastías ocupan el trono de Castilla por la voluntad de la nación desde tiempo inmemorial ya que sin la nación fuente y origen de la majestad, no habría monarcas... La autoridad regía que éstos ejercen se deriva del indispensable principio de la soberania nacional..." ". El Eco, otro día, sentenciaba: "Cuando el eterno principio de la soberanía nacional se trueca en el comienzo de una real cédula, de una carta de naturaleza o de un mero despacho judicial; cuando se roba a España el derecho de constituir la forma y condiciones de su gobierno... la nación española no se puede vestir de gala, porque su íntimo dolor se niega a la hipocresía y a la infamia..." ${ }^{12}$.

9 DSC, 1 noviembre 1844, págs. 185-6.

10 DSC, 11 noviembre 1844, pág. 390.

"El Espectador, 25 octubre 1844.

12 Eco del Comercio, 4 noviembre 1844. 


\section{LA SOBERANÍA CONJUNTA Y LA FÓRMULA DE PROMULGACIÓN}

Los promotores y defensores de la reforma situaban, frente al principio de la soberanía nacional, el de la soberanía conjunta de la Corona y de las Cortes.

El Ministerio, en la Exposición previa al proyecto de reforma, defendía y justificaba este último principio en los términos siguientes: "...De esta manera se procura en cuanto cabe la inapreciable ventaja de dar por base a la Constitución la voluntad acorde del Monarca y de los elegidos de la nación, evitando pretensiones exageradas por uno y por otro extremo que suelen principiar por celos y rivalidades y terminar por escándalos y trastornos...". El Ministro de la Gobernación, PIDAL, poco después, al discutirse el voto particular de ISTÚRIZ, glosaba aquella presentación en los términos siguientes: "...Lo que nosotros queremos es una ley fundamental en la cual el Poder real y el Poder legislativo de consuno intervengan; es decir, que no queremos dejar a un solo poder su formación, sino que queremos que tengan parte en ella el otro Poder del Estado; queremos una ley fundamental hecha por las Cortes y sancionada por una Reina en su menor edad: éste será su complemento; éste le dará un carácter de estabilidad.... ${ }^{13}$.

La teoría fue desarrollada con brillantez en el dictamen de la Comisión del Congreso. El dictamen advertía que los enemigos de la reforma eran de dos especies: la una comprendía a aquellos "que hacen venir del cielo la soberanía y la asientan en el Trono", la otra a aquellos "que la hacen venir del pueblo y la asientan en una congregación de sus representantes...". La Comisión consideraba que no era tarea suya entrar "en contienda sobre metafísica constitucional, ni llevar la luz de la discusión a tan escondidas y lóbregas regiones...". La Comisión pretendía apoyarse en la historia y en la realidad; de esta manera llegaba a la conclusión siguiente: "Los pueblos miran como cosa sencilla y natural que las reformas políticas procedan de aquella suprema autoridad de donde

13 DSC, 30 octubre 1844, pág. 148. En una línea de pensamiento parecida, Miraflores, en aquellos días, escribió: "Si los demócratas pudieron un día acusar al Estatuto de ser un don exclusivo del Trono sin participación del pueblo, la Constitución de 1837 puede con razón ser tildada por los hombres monárquicos de haber sido formada sin participación de la Corona.Y ello es una verdad que la Ley fundamental en España, para que sea una obra sólida y aceptable, han de intervenir en ella el elemento Real y popular, combinados ambos con armonía y acuerdo". Citado en CAMPOAmor, Historia crítica de las Cortes reformadoras, en Obras Completas, tomo II, 1901. 
procede como de un manantial fecundisimo, así las leyes protectoras de los ciudadanos como las que guardan los Imperios, así los consejos de la paz como los consejos de la guerra. La potestad constituyente no reside sino en la potestad constituida, ni ésta es otra en nuestra España, sino las Cortes con el Rey. Lex fit consensi populi et Constitucione Regis: esta máxima de nuestros padres, sublime por su misma sencillez, ha llegado hasta nosotros vencedora de los tiempos y de las revoluciones..." ${ }^{14}$.

Aqui no se especulaba con principios filosóficos ni se definían doctrinas, sino que se constataba escuetamente lo que en España habia sido, a un tiempo, historia y derecho, a saber: todo acto de soberanía se había decidido y ejecutado con el concurso del Rey y de sus estados. Nada se había hecho sin el Rey o sin las Cortes; todo se había hecho, todo podía hacerse con el Rey y las Cortes. De esta manera, las doctrinas que proclamaban, con pretensiones excluyentes, la soberanía real o la nacional -aparte el problema de su validez intrínseca- eran rigurosamente inaplicables a la nación española, donde la potestad real y la representación popular ni se concebían separadamente ni se contraponian polémicamente, sino que, nacidas en el mismo seno histórico, habian compartido a través de siglos y afanes la soberanía plena y habían constituido en su existencia dinámica y en su colaboración cotidiana el Reino de las Españas. En otros lugares, la potestad real y la representación popular podian tal vez reputarse entidades diferentes $y$ aun contrapuestas; en la historia de España formaban unidas a la Constitución de la Monarquia. Ninguna de tales instancias podía atribuirse de manera exclusiva el poder constituyente ni la facultad ordenadora sobre la otra: el poder constituyente monárquico y el poder constituyente popular se disolvían en el poder constituyente de la historia, que confería su legitimidad a la una y a la otra ${ }^{15}$.

La adopción del principio de la soberanía nacional o el de la soberanía conjunta explican la distinta fórmula de promulgación utilizada por la Constitución del 37 y la del 45.

El Preámbulo de la primera determinaba que las Cortes Generales decretaban y sancionaban la Constitución de la Monarquía. MARTíNEZ

14 El texto del dictamen en loc. cit.

15 Diez del Corral, a quien se sigue de cerca en estas observaciones, escribe: «La coparticipación de la soberanía entre el Rey y las Cortes como producto germinado de un unitario proceso histórico, que de una manera implicita pero clara se encontraba esbozada en el Estatuto Real y que será luego desarrollada ampliamente por Cánovas se encuentra ya ampliamente reconocida en la Constitución del 45...n: El liberalismo doctrinario, págs. 503-4. 
DE LA ROSA, ahora, censuraba severamente tal fórmula. De una parte advertía que en aquél aparecía borrada enteramente la autoridad real, "en términos que no se sabe si los Diputados que le han hecho han llegado a una isla desierta y forman primero un Estado, y luego fundan un Trono y después llaman a ocuparle a la Reina Doña Isabel II. No; los Diputados de la Nación no pudieron alterar las bases de la Monarquía española; y no fueron ellos los que dieron los derechos al Trono y a la augusta Reina nuestra Señora, a la hija de cien Reyes...". De otra, quizás exagerando la crítica, juzgaba que el Preámbulo suponía virtualmente un desprecio y aun un insulto que era obligado borrar para el Trono: los legisladores del 37 no habian visto o no habían querido ver que, al frente de ellos, existía aquella Monarquía y Trono con catorce siglos de antigüedad: " $i Y$ legislan como si tal Trono no existiese, y escogen hasta las frases y palabras que más pueden ofenderle, diciendo que la nación, en uso de su soberanía, decreta y sanciona aquella Constitución! Hay aquí un refinamiento que humilla al Trono y que no debe consentir la generosa Nación española...." ${ }^{16}$.

El Preámbulo de 1845, acorde con el principio de la soberanía conjunta, determinaba que la Corona, en unión y de acuerdo con las Cortes, decretaban y sancionaban la nueva Constitución. La fórmula suscitó el reparo aislado de POSADA; pero el Congreso y el Senado la aceptaron sin dificultad. En la primera Cámara, DÍAZ CID advertía que el texto sellaba un pacto entre los dos altos Poderes: “...Ambos van a ser igualmente representados; ambos van a concurrir a esta obra común y va a establecerse esta alianza o pacto social...". Y reiterando el mérito de la fórmula, añadía: " "...Los dos altos Poderes depositarios de la soberanía decretan y sancionan. No puede desearse mayor exactitud en el Preámbulo; no puede elevarse a mayor altura la dignidad de ambos Poderes; ninguno se rebaja, ninguno se menoscaba; ambos tienen la misma representación y decoro; ambos se presentan con la misma dignidad cuando van a darse las leyes fundamentales del país...." 1 . En la Cámara Alta, GARCíA GOYENA, conjugando la valoración política con la precisión técnica, reproducía escuetamente el mismo argumento y consideración: “...Con la reforma -decíava a hacerse una alianza solemne entre el Rey y el pueblo. Ninguna Constitución podrá en adelante parecer más legítima y majestuosa que la española. No será una Constitución otorgada graciosamente como merced, ni tampoco una Constitución impuesta por la violencia...." ${ }^{18}$.

16 DSC, 11 noviembre 1844, pág. 391.

17 DSC, 12 noviembre 1844, pág. 411.

18 DSC, 21 diciembre 1844, pág. 143. SÁnChez Agesta advierte que el nuevo Preámbulo supone una exaltación del poder de la Corona: "La soberania nacional -escribe- suponía un primado de las Cortes que la representaban; esta soberanía 
Los elementos y la prensa progresista censuraron con acritud $y$ reiteración la fórmula. Cuando todavía se encontraba en fase de discusión, El Eco del Comercio escribía: "...Las leyes políticas que determinan y declaran la organización fundamental y la voluntad del único soberano verdadero no se decretan y sancionan por el Monarca y las Cortes, sino que se decretan y sancionan sólo por las Cortes Constituyentes y se aceptan por el Rey si está conforme con la expresión soberana de sus votos... Es falso que competa a la Reina, fuera de la aceptación y el juramento, ninguna parte del poder constituyente. La Reina que no discute ni vota, la Reina que no es ni puede ser miembro de la Asamblea popular, ¿ha de intervenir en el decreto y en la sanción de las leyes fundamentales? ¡Qué delirio! ¡Qué degradación para los pueblos!...». El artículo continuaba explicando y desarrollando el argumento que, con mayor o menor razón, ligaba al juramento prestado por Isabel II: "...Isabel II, reina de la España por la Constitución de la Monarquía que es la de 1837, ¿podrá intervenir en su modificación y decretar y sancionar su reforma siendo reina por aquel pacto $y$ habiendo jurado su observancia? ¿No se advierte que cuando se le haga decir decreto $y$ sanciono se pone en sus augustos labios una fórmula de usurpación y una voz de perjurio?... ¡Un rey decretar $y$ sancionar leyes constitucionales!..." ${ }^{19}$.

\section{LOS ANTIGUOS FUEROS Y LIBERTADES}

En el Preámbulo de la Constitución de 1812 se afirmaba que las Cortes Generales y extraordinarias de la Nación estaban convencidas "de que las antiguas leyes fundamentales de la Monarquía, acompañadas de las oportunas providencias y precauciones, que aseguren de un modo estable y permanente su entero cumplimiento", podrían promover la gloria, la prosperidad y el bien de toda la nación ${ }^{20}$. Por su parte, en la exposición previa al Estatuto Real de 1834, los Ministros le decían a la Reina Gobernadora: "A V.M. está reservada la gloria de restaurar nuestras antiguas leyes fundamentales, cuyo desuso ha causado tantos males por el espacio de tres siglos y cuyo restablecimiento por la augusta

histórica del Rey y las Cortes supone, cuando menos, una equiparación de ambas instituciones que cede fácilmente en una primacia de la Corona como órgano estable. Éste es uno de los propósitos políticos más manifiestos a que se encamina la reforma constitucional». Historia..., pág. 249.

19 Eco del Comercio, 25 octubre 1844.

20 El texto en SeVILLA Andrés: Constituciones..., tomo l, pág. 161. 
mano de V.M. será el más próspero presagio para el reinado de su excelsa Hija" ${ }^{21}$. Los dos textos, tan diferentes en su fundamento y en su contenido, con aquellas afirmaciones parecidas, parecian inspirarse en motivaciones varias: la creencia honesta e ingenuamente sentida de que los principios y preceptos que recogían eran, realmente, la vestidura antigua de las máximas e instituciones de la Monarquía; el deseo de dotar a su obra politica de una autoridad que hundía sus raíces en la historia; el deseo de conjugar los nuevos modos de gobierno con las viejas leyes y costumbres de la nación.

El Preámbulo de la Constitución de 1845, siguiendo la misma línea y trayectoria, quería «regularizar y poner en consonancia con las necesidades actuales del Estado los antiguos fueros y libertades de estos Reinos y la intervención que las Cortes han tenido en todos tiempos en los negocios graves de la Monarquía".

La tesis, ahora, como en las épocas anteriores, suscitó objeciones procedentes de distintas líneas políticas. El 11 de noviembre, TEJADA, en el Congreso; el 12, POSADA, en la misma Cámara, y a fines de diciembre, MIRAFLORES, en el Senado, explicaban aquellos reparos en los términos que a continuación se expresa.

A) TEJADA, situado en línea monárquica pura, negaba la teoría del restablecimiento de los antiguos fueros y libertades de la Monarquía: era una falsedad con la que en distintas épocas, desde 1812, se había intentado deslumbrar al país para llevar al gobierno «nuevos y errados sistemas con la apariencia de rendir un homenaje a nuestras antiguas leyes y costumbres monárquicas...". Los autores de la Constitución del 12 pretendian que era sólo la renovación de aquéllas; los del Estatuto habian afirmado lo mismo pero, al propio tiempo, "gobernando democráticamente, contra el espíritu y letra de su ley verdaderamente monárquica, permitiendo a otros elevar fuera de su cimiento un sistema sólo propio de la Constitución de 1812...". Ahora, los autores de la reforma sostenían parecida pretensión que estaba desmentida por la historia y por nuestro derecho público. Todo el discurso de TEJADA suponía implícitamente un rechazo de la tesis restauradora; pero, además, en términos más expresos y directos, advertía que las modernas Constituciones $y$, por tanto, la que se proponía, no se fundaba en los mismos principios que la antigua y veneranda de Castilla: en ésta no se encontraba la dependencia anual del Rey para cubrir las obligaciones ordinarias y permanentes del Estado; no existía la libre elección popular; no se reconocía la iniciativa de las leyes a los individuos, pero ni aun a los Cuerpos que votaban sobre aqué-

21 El texto de id., id., pág. 257. 
Ilas; finalmente, en los textos actuales se encontraban muchas y singulares disposiciones que en tiempos pasados no se habían conocido: "...Esto - Concluía- no es armonizar, como dice el Gobierno; es trastornar profundamente... Aquí no se enlaza lo nuevo con lo antiguo; se destruye lo antiguo para reemplazarlo exclusivamente con lo nuevo... ${ }^{22}$.

B) Posada presentó una enmienda al Preámbulo: de ella, en este lugar, nos interesa retener dos extremos. De una parte, juzgaba anacrónica la pretensión de regularizar y actualizar los antiguos fueros y libertades de estos Reinos: "¿De qué fueros y libertades - preguntaba- se habla aquí? ¿Se habla del tiempo que los fueros y libertades no eran de derecho público? Entonces los pueblos tenían unas libertades, los ricos y los nobles tenian otras; ahora no tienen libertades, sino libertad. Esas voces, fueros y libertades se usaban como propiedad en el tiempo en que no eran el derecho común; ya no tenemos fueros antiguos ni libertades: aquéllos eran en los principios; hoy están consignadas en el derecho común...". De otra parte, la referencia a la intervención que las Cortes habían tenido en todos los tiempos en los negocios graves de la Monarquía era inexacta: "...Señores -advertía-, esto es faltar a todas las tradiciones históricas, a todo lo que nos dice la historia que hemos podido leer...». Las Cortes no habian tenido aquella intervención en los siglos XVII y XVIII; no podía reputarse como tal la mezquina que tenía la Diputación General de todos los Reinos, la de ponerse en las leyes la fórmula o calificación como si fuese hecho en Cortes: "Esto —concluia- sería cambiar los nombres por las cosas... No se debe poner en el Preámbulo de la Constitución una cosa que está en duda y que los más no saben: cuando se busca el apoyo de la historia, se debe buscar un apoyo verdadero, no ficticio..." ${ }^{23}$.

C) Finalmente, el marqués de Miraflores, defensor y partidario de la reforma, señalaba que el recurso a las leyes fundamentales en el Constitucionalismo español había llegado a ser un expediente tan singular como inexacto: "Yo, señores - decía-, al leer en el preámbulo de la Constitución de 1812 y confieso que lo mismo me sucedió con el Estatuto, que no se hacía más que restablecer nuestras antiguas leyes admiré la fértil imaginación de los autores de esta idea, que sería ingeniosa, sí, pero aún más inexacta que ingeniosa. ¡Nuestras antiguas leyes restablecidas en la Constitución de 1812 ni aun en el Estado...! Las doctrinas, las circunstancias y los sistemas politico-sociales eran tan diversos que cualquier comparación detallada sería desconcertante: "Comparación curiosa fuera - añadía - la que resultaría de la Constitución de 1812, el Estatuto y la 
Constitución del 37, con los fueros de León, de Nájera, de Burgos y de Sepúlveda...". Las referencias y las citas históricas tenían un sentido y un valor muy limitado porque los sistemas modernos de gobierno no fijaban sus raíces en las viejas doctrinas e instituciones medievales, sino en las nuevas doctrinas representativas. "Señores -concluía-, valga la verdad. La Constitución del 12, el Estatuto, la Constitución del 37, son una cosa que tiene menos relación con las antiguas leyes de León y Castilla que el Alcorán con el Evangelio. La Constitución del 12, el Estatuto, la Constitución del 37 y la que resultará después de reformada ésta es una cosa enteramente diversa: es la aplicación de doctrinas nuevas.... ${ }^{24}$.

Esta tesis negativa, defendida por TEJADA, por POSADA y por MIRAFLORES, era, seguramente, bastante más exacta y real que la restauradora. Ésta se encontraba en los textos de 1812 y de 1834 en los términos ya señalados: los legisladores del 37 la borraron transitoriamente. Ahora volvía a resurgir y lo haría también en la Constitución de 1876 . Pero la tesis restauradora - según ha señalado SÁNCHEZ AGESTA - curiosamente se encuentra también apoyando tesis revolucionarias. En 1855, la soberanía nacional representada en una sola Cámara fue defendida invocando la presencia del pueblo en la Monarquía de los Reyes Católicos, su acción en los ejércitos de Carlos V y Felipe II y su esfuerzo heroico en los días de 1808. Y en las Cortes de 1869 se defendió la libertad religiosa invocando la tradición medieval de convivencia entre católicos y arrianos y entre católicos, musulmanes y judios para concluir que la intolerancia era lo moderno y la libertad religiosa lo antiguo ${ }^{25}$.

\section{CONSTITUCIÓN INTERNA Y CARTA CONSTITUCIONAL}

El Preámbulo, tal como lo había redactado el Gobierno, precisaba ya que el Trono y las Cortes querían modificar la Constitución de 1837. El dictamen de la Comisión advertía que el poder constituyente residía en la potestad constituida y ésta en España era la de las Cortes con el Rey. De este modo, la futura Constitución no crearía el Trono y la representación nacional; sino que, al contrario, estos dos poderes revisarían la Ley politica de 1837. En otros términos, existían instituciones anteriores a la Ley constitucional: existía una Constitución histórica, interna, previa, que las Constituciones escritas se limitan a articular.

24 Miraflores, Marqués de: Memorias, tomo II, pág. 354.

25 SánChez Agesta: Historia..., pág. 33. 
La doctrina - lo ha señalado SÁNCHEZ AGESTA - no es una elaboración actual que utilice materiales extraidos de la discusión parlamentaria, sino que los hombres del 45 tuvieron conciencia de sus matices y consecuencias ${ }^{26}$.

El Ministro de la Gobernación, PIDAL, en el examen del voto particular de ISTÚRIZ fue posiblemente quien primero expuso en el Congreso la teoría. PIDAL partía de la consideración de que en toda nación constituida existen formas mediante las que el Poder público se manifiesta: "...El Poder público — precisaba — se revela de diferentes modos y en una nación se revela personalizándose en un individuo o en una dinastía, y en otra se revela dando ese Poder social a una Asamblea... En España se ha revelado en dos grandes instituciones, en dos grandes legitimidades $y$ éstas son el Trono y las Asambleas Nacionales... En todas las épocas desde que descubre la existencia de la Monarquía española, yo veo el Trono y al lado de él veo también una Asamblea: he aquí los dos grandes polos sobre los que gira la Monarquía española; y es imposible que una ley secundaria, cual es la que hace la repartición de estas dos grandes legitimidades, sea superior ni igual a ellas. Todo lo que arregla las relaciones entre los Poderes es inferior en mucho al Trono, es inferior en mucho a la representación nacional...". En suma: la Constitución interna y esencial era el edificio; la Constitución escrita, su parte arquitectónica: «Ésta puede variarse y el edificio será siempre el mismo...." ${ }^{27}$.

La Constitución es, pues, el hecho necesario de la organización de un pueblo como condición para su misma existencia; es la formación espontánea de órganos de poderes como sedimentación de un proceso histórico. Las leyes políticas -PIDAL las califica de secundarias - tienen un rango sensiblemente inferior y son la fórmula escrita que en cada momento dibuja las relaciones entre aquellos poderes del modo que se juzga más oportuno atendida la circunstancia histórica concreta ${ }^{28}$.

La exposición de PIDAL fue expresamente recogida y desarrollada, dos días después, siempre en el Congreso, por SEIJAS, quien, quizás con mayor expresividad terminológica, proponía una distinción entre Constitución y Carta o leyes constitucionales. La Constitución de un Estado es "la relación de las grandes instituciones que han nacido, desarrollado y desenvuelto con la sociedad misma... Estas instituciones se parecen al cimiento de un gran edificio que, obra del arquitecto y parte del edificio mismo, sirve, sin embargo, de fundamento y base a todo él. Las grandes 
instituciones nacen con las sociedades, crecen como ellas y crecen sin la voluntad de los hombres, atendiendo a sus instintos, a sus inclinaciones y a las muchas circunstancias que determinan el giro de los pueblos...". Las Cartas constitucionales eran y son otra cosa: son "la fórmula escrita que demuestra esas relaciones entre las instituciones de los pueblos; son la historia abreviada de los mismos sancionada por el Poder público..." ${ }^{29}$.

Las Constituciones, pues, están formadas por las grandes instituciones de una nación y van ligadas a su existencia, a su fisonomía, a su proyección histórica. En cambio, las Cartas constitucionales son el modo concreto y peculiar de regular, en un momento histórico determinado, la organización y relaciones de aquellas instituciones para corregir los defectos que la experiencia hubiese puesto de manifiesto o que nuevas circunstancias políticas exigiera. Una Carta constitucional es sólo la especificación, la concreción, la glosa de la Constitución interna.

La Constitución de la nación española estaba formada por el Trono y las Cortes: era o debía ser intocable. La Carta Constitucional de 1837 era sólo un modo de regular las relaciones entre las dos instituciones: era susceptible de reformas y mejoras.

La tesis fue de algún modo completada por ALCALÁ GALIANO, quien parecía distinguir entre Constitución interna o material y Constitución en sentido formal. ALCALÁ juzgaba que lo que en aquel momento se examinaba $y$ discutía no era propiamente una reforma de la Constitución: "...Es inexacto llamar a la modificación de estos artículos que se propone reformar la Constitución...". Y perfilando su pensamiento, añadía: "...Yo entiendo por Constitución de un Estado, no lo que han entendido otros que limitan este nombre a los que contiene el texto de un libro bajo cuyas disposiciones se forman las leyes, sino el conjunto de lo que real y verdaderamente constituye el país... Algo de eso suele estar fuera del mismo texto, así como también suele haber dentro de él algo que no puede mirarse como propiamente constitutivo...". ALCALÁ reconocía que si todos convenían en Ilamar Constitución a un libro que recogía ciertos principios $y$ dogmas, podía resultar arbitrario $y$ arriesgado presentar otro concepto de tal palabra. Pero en defensa de su tesis argüia que nadie daría la misma importancia a la reforma que ahora se proponia que a la que atribuyese al Rey sólo la facultad de formar las leyes; o las de que las contribuciones se impusieren y cobrasen por la exclusiva voluntad de aquél; o la de que se suprimiese la responsabilidad de los Ministros: todas estas mudanzas o cualquiera de ellas no tendrian el mismo valor que las 
que ahora se proponian. "Señores - concluía-, a mi entender las Constituciones no se reforman, se varian; lo que puede reformarse son unas leyes que están en las Constituciones, pero que no son las Constituciones.... ${ }^{30}$.

En conclusión: la teoría era congruente con los principios de que partían los promotores y defensores de la reforma. Si se niega la existencia de un poder constituyente en sentido estricto, no cabe admitir que se pueda dar una Constitución enteramente nueva; sino sólo que se reforme la existente ${ }^{31}$. Pero, además —conviene subrayarlo de modo muy especial-, la teoría respondía quizás al deseo de demostrar que podía modificarse, sin grave problema ni quebranto, la Ley Fundamental de 1837: era una simple Carta constitucional, distinta e inferior a la Constitución interna y permanente ${ }^{32}$.

\section{CONSTITUCIÓN REFORMADA O CONSTITUCIÓN NUEVA}

Si se deja aparte - por valiosa que sea- la teoría de la Constitución interna y se desciende a la comparación concreta de los textos, surge el problema de determinar si el de 1845 era sólo una reforma del de 1837 o uno nuevo.El tema quedó planteado también en el Preámbulo, cuyo análisis finaliza en este apartado.De una parte, presenta a la Corona y a las Cortes "modificando al efecto la Constitución promulgada en 18 de Junio de 1837»; de otra, en su frase final señala que las dos potestades

30 DSC, 2 noviembre 1844, pág. 212. La misma tesis parece apuntar en algunas páginas de sus Lecciones. Sobre todo ello, véase GaRRoREnA: El Ateneo de Madrid y la teoría de la Monarquia liberal 1836-1847, Madrid, 1974, págs. 361 y ss.

31 Diez del Corral: El liberalismo, pág. 504. Véase, sin embargo, lo que se señala en el apartado siguiente.

32 Sánchez Agesta: Historia..., pág. 200. Este profesor, que dedica especial atención al tema, resume la teoría en los siguientes términos: "...Hay, pues, instituciones preexistentes a la ley constitucional; hay, pues, una Constitución interna histórica, que las Constituciones escritas no hacen sino articular. No es siquiera un pacto lo que esta Constitución escrita supone, sino una revisión y organización de sus relaciones que el Rey y las Cortes hacen de mutuo acuerdo... La Constitución interna, es, pues, un hecho anterior a toda declaración jurídica formal... Es, además, una legitimidad histórica concreta, opuesta como tal a la legitimidad abstracta y revolucionaria del poder constituyente fundado en la soberanía nacional. El broche de la doctrina es el análisis de las instituciones que fundan su legitimidad en esa tradición actual que se impone como un hecho: La Corona y una asamblea representativa. El dualismo doctrinario de la Monarquía constitucional encuentra así una justificación sociológica e histórica..." (pág. 200). 
vienen «en decretar y sancionar la siguiente Constitución de la Monarquía española...".

\section{La tesis de la reforma}

La tesis de la mera reforma encuentra apoyo en los textos oficiales $y$ en la discusión parlamentaria.

La Exposición preliminar al Decreto electoral manifestaba que los Ministros se proponian "llevar la mejora y la reforma hasta la misma Constitución del Estado...". El proyecto del mismo Ministerio trataba de explicar a la Reina y a la opinión pública el pensamiento de aquél "respecto a la reforma constitucional..."; ; y señalaba que los Ministros querian limitarse en orden a las reformas "a aquellas que han estimado necesarias o convenientes...". Por último, después de enumerar unas y otras, concluían en los siguientes términos: «...Tales son las reformas principales que se proponen vuestros Secretarios de despacho... Por los mismos que desean que se arraiguen en España instituciones semejantes a las que tanto poder $y$ esplendor están dando a otras Monarquías no vacilen en aconsejar, en cumplimiento de su deber, que se hagan en la Constitución aquellas alteraciones $y$ mejoras que corrigiendo sus defectos de que no está exenta ninguna obra humana aseguren para lo venidero su puntual y exacto cumplimiento...".

La Comisión del Congreso dividía su dictamen en dos grandes apartados. El primero se titulaba: «Legalidad, oportunidad y urgencia de la reforma". El segundo: "Conveniencia de la reforma que la Comisión propone». En aquél, de una parte, se señalaba que "sólo reformando la Constitución en aquellos puntos que ofrecen un obstáculo al afianzamiento del orden y a la completa organización de la administración pública, será cosa hacedera plantear de una vez todas las leyes orgánicas que son el complemento de nuestras instituciones..."; de otra, "que ninguna ocasión es más favorable para corregir las faltas de una Constitución hecha en tiempos turbados y de minorías que aquella en los que comienzan a despejarse en que el Rey, llegado a su mayor edad, toma en sus manos el cetro de sus mayores. El segundo apartado, después de razonar las diferentes modificaciones propuestas, concluia asi: "Tales son las reformas que la Comisión estima necesarias en la ley fundamental del Estado: con ellas, siendo aprobadas, la Constitución de la Monarquía descansará sobre cimientos firmísimos como obra en la que han puesto sus manos, en presencia de las Naciones, las dos grandes potestades de la tierra, el Trono y el pueblo...". 
La continuidad entre la Constitución de 1837 y la que se pretendia elaborar fue expuesta reiteradamente en el curso de las discusiones mantenidas en las dos Cámaras. "...La que hoy es ley fundamental del Estado - decía POSADA - habrá de serlo después, porque aunque reformada, siempre será la Constitución de 1837..." ${ }^{33}$. «...La Constitución del 37 —advertía BARRIO AYUSO- no va a morir hoy; va a quedar sin algunas manchas que afeaban, y más pura, flexible y mejor que antes estaba..." ${ }^{34}$. "Esta Constitución - denunciaba TEJADA - será la continuación en algo modificada de la de 1837 " ${ }^{35}$. La tesis fue expuesta y defendida más ampliamente por CALDERÓN COLLANTES partiendo de una distinción entre las bases y los preceptos inferiores de la Constitución. "Cuando la reforma - decia- se hace sobre alguna de las bases de la Constitución, entonces la reforma es fundamental; pero cuando recae sobre artículos secundarios, dejando intactas las bases, como sucede precisamente en la reforma que nos propone el Gobierno, entonces la reforma es muy secundaria...". La Constitución del 37 se apoyaba en dos bases esenciales: la prerrogativa que el Trono necesitaba para ejercer su acción y las garantías necesarias a la nación para su bienestar. "¿Y nosotros tocamos a ninguna de ellas? No... No tocamos a las prerrogativas del trono, así como tampoco tocamos a ninguna de las garantías de las libertades públicas...". Y refiriéndose concretamente a éstas últimas, mencionaba la facultad de las Cortes de votar las contribuciones, la inviolabilidad de los Diputados, la inamovilidad del Poder Judicial: “...De consiguiente -concluía-, no tocamos las bases de la Constitución; ni a las que son prerrogativas del Trono ni a las que sirven de garantía a las libertades públicas...." ${ }^{36}$.

\section{Una Constitución nueva}

Esta tesis contaba también con apoyos directos y formales. El Preámbulo, en el proyecto del Ministerio, en los dictámenes de las Comisiones de ambas Cámaras y en el texto final, señalaba que la Corona y las Cortes venían en decretar y sancionar la siguiente Constitución de la Monarquía española. La reforma de la de 1837 no se tradujo en la publicación de un texto refundido de la misma, sino de una Ley fundamental que apareció como nueva y diferente. En ningún texto ni en ningún momen-

33 DSC, 28 octubre 1844, pág. 107.

34 DSS 21 diciembre 1844.

35 DSC, 11 noviembre 1844, pág. 382.

36 DSC, 1 noviembre 1844, pág. 188. 
to de la discusión se previó que se publicase una nueva edición de la Constitución del 37, colocando las alteraciones acordadas en el lugar que por numeración le correspondiese. En fin: en numerosos discursos parlamentarios se hizo referencia a la nueva Constitución.

Los progresistas, tan pronto se hizo público el proyecto del Ministerio y, sobre todo, el dictamen de la Comisión del Congreso, entendieron $y$ afirmaron que se trataba de una nueva Constitución de la que se sentían por completo insolidarios. El Eco del Comercio, comentando este último texto, escribía: "...¿Para qué pueblo es esa Constitución de 1844 ? No es ciertamente para los partidarios de la libertad de imprenta, del juicio por jurados, del gobierno civil y político, de las asociaciones pequeñas consagradas por la historia de doce siglos continuos, de la abolición de los fueros especiales, de la soberanía nacional, de la milicia ciudadana, de la amplitud electoral... No es siquiera una Constitución para los absolutistas, sino una Constitución para el absolutismo. No es la Constitución de los grandes partidos que no han tenido parte en ella y la rechazan... ${ }^{37}$. Cuando la discusión parlamentaria había terminado ya en el Congreso, El Espectador advertía que los principios sobre los que descansaba el texto que se estaba elaborando no eran los de ningún partido numeroso: «....Ni pertenecen al partido liberal que no admite ni puede admitir una Constitución que no reconozca la soberanía de la nación, como fundamento de todas las teorias de su gobierno, como el primer dogma de su credo político, ni pertenecen al partido realista que no se aviene a otra clase de gobierno que el que abandona todo el poder público sin restricción, sin cesiones de ninguna clase a las manos del monarca...". Los dos textos progresistas cuidaban, pues, de subrayar, en términos parecidos, la soledad política que acompañaría a la nueva Constitución ${ }^{38}$.

Por último, los textos y proyectos que aparecen después de 1845 consideraban a la Constitución de este año como distinta de la de 1837. El proyecto de BRAVO MURILLO de 1852, al explicar la sucesión de nuestras Constituciones, decía: “...Así, a la Constitución de 1812 sucedió la de 1837 y a ésta la de 1845, adaptándose en cada una de ellas las reformas que al parecer exigían la experiencia y las necesidades de la respectiva época...". El proyecto de RONCALLI, en 1853, pretendía asimismo la reforma de la Constitución de 1845. El dictamen de la mayoría de la Comisión y los votos particulares que acompañaban a las bases para preparar la Constitución nonnata contenian referencias, generalmente críticas, a la Constitución del 45. El Decreto de 15 de septiembre de 1856, que cierra el

37 Eco del Comercio, 6 noviembre 1844.

38 El Espectador, 10 diciembre 1844. Los textos citados, sobre los que más adelante se volverá, en SEVILLA Andrés, Constituciones..., tomo 1. 
bienio progresista, restablecía la Constitución del 45, con un Acta Adicional que fue derogada un mes después dejando vigente en toda y sola su integridad aquélla.

En suma: la trayectoria completa de la Constitución de 1845, los proyectos y normas citadas, que comprenden la década siguiente a su promulgación, son suficientes para demostrar que fue considerada siempre como un texto diferente del de 1837: como algo distinto de una simple reforma de la misma. 


\section{BIBLIOGRAFÍA}

Alcalá Galiano, A: Historia de España desde los tiempos primitivos hasta la mayoría de edad de la Reina Dona Isabel II, redactada y anotada con arreglo a la que escribió en inglés el doctor Dunham, por don..., Madrid, 1846, tomo VIl.

Alcalá Galiano, A.: Lecciones de Derecho Político, ed. 1984.

Álvarez Conde, E.: "La Constitución española de 30 de junio de 1876. Cuestiones previas", en Revista de Estudios Políticos, nueva época, n. 3 , 1979, pág. 79 y ss.

Aribau Buenaventura, C.: Reflexiones sobre la inoportunidad de la proyectada reforma constitucional, Madrid, 1844.

ARTOLA, M.: Partidos y programas políticos 1808-1936, Madrid, 1975.

BALmes, J.: Escritos políticos, en Obras Completas, BAC, 1950, tomos VI y VII.

Bermejo, I. A.: La Estafeta de Palacio, Madrid, 1871.

Bertelsen Repeto, R.: El Senado en España, Madrid, 1974.

Borrego, A.: De la organización de los partidos en España considerada como medio de adelantar la educación constitucional de la nación y de realizar las condiciones del gobierno representativo, Madrid, 1855.

- Manual electoral para el uso de los electores de la opinión monárquico-constitucional, Madrid, 1837.

Borrow, G.: La biblia en España, Madrid, 1974.

Bravo Murillo, J.: El proyecto de reforma de 1852, en Opúsculos, tomo IV.

Burgos, J.: Anales del reinado de doña Isabel II, Madrid, 1850.

CAmpoamor: Historia crítica de las Cortes reformadoras, en Obras Completas, tomo II, 1901.

Cánovas Sánchez, F.: El partido moderado, Madrid, 1982.

Casanova Aguilar, l.: Aproximación a la Constitución nonnata de 1856, Murcia, 1985.

Castillo y Ayensa: Historia crítica de las negociaciones con Roma desde la muerte del Rey D. Fernando VII, Madrid, 1859, tomo II. 
Colomer Viadel, A.: El sistema político de la Constitución española de 1837, Madrid, 1989.

Comellas, J. L.: Los moderados en el poder. 1844-1845, Madrid, 1970.

De Esteban, J.: Las Constituciones de España, Madrid, 1981.

Díez del Corral, L.: El liberalismo doctrinario, Madrid, ed.1956.

Donoso CoRTÉs, J.: Obras Completas.

Fernández de Córdoba, F.: Mis memorias íntimas, en B.A.E., 1966.

FeRnÁndez de los Ríos, A.: Estudio histórico de las luchas políticas en la España del siglo XIX, Madrid, 1879.

Fernández Segado, F.: Las Constituciones históricas españolas, Madrid, 1981.

Flores, A.: La sociedad de 1850, ed. 1968.

Garrorena Morales, A.: El Ateneo de Madrid y la teoría de la Monarquía constitucional, 1836-1847, Madrid, 1974.

JANKe, P.: Mendizábal y la instauración de la Monarquía constitucional en España (1790-1853), Madrid, 1974.

Jaumenden, E.: Catecismo razonado o explicación de los artículos de la Constitución política de la Monarquía española publicada el 18 de Junio de 1837, Barcelona, 1839.

Jover Zamora, J. M.: "Situación social y poder político en la España de Isabel II", en Historia social de España, Siglo XIX, Madrid, 1972, Prólogo.

Lafuente, M.: Historia general de España desde los tiempos primitivos hasta la muerte de Fernando VII. Continuada desde dicha época hasta nuestros días por $D$. Juan Valera con la colaboración de $D$. Andrés Borrego y D. Antonio Pirala, Barcelona, 1890, tomo XX.

LÓPEZ, Joaquín M.ạ: Curso político constitucional, ed. 1987.

MaRCuello Benedito, J. I.: La práctica parlamentaria en el reinado de lsabel II, Madrid, 1986.

MARICHAL, C.: La revolución liberal y los primeros partidos políticos en España, 1834-1844, Madrid, 1980.

MARLIANI, M.: La Regencia de D. Baldomero Espartero y sucesor que la prepararon, Madrid, 1870. 
MARTINez de LA Rosa, F.: Bosquejo histórico de la politica de España desde los tiempos de los Reyes Católicos hasta nuestros días, B.A.E., tomo VIII.

- Espiritu del siglo, B.A.E., tomos V-VIII.

Medina Muñoz: "La reforma constitucional de 1845", en Revista de Estu-

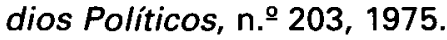

Miraflores, Marqués de: De la reforma de la Constitución de 1845 verificada en 1857, Madrid, 1864.

- Juicio imparcial y breve acerca de la cuestión de reforma de la Constitución de 1837, Madrid, 1844.

- La reforma de 1852, Madrid, 1852.

- Memorias del reinado de Isabel II, B.A.E., ed. 1954.

PABÓN, J.: El régimen de los generales, Madrid, 1983.

PaCHeCo, J. F.: Historia de la Regencia de la Reina Cristina, Madrid, 1841.

- Lecciones de Derecho político, ed. 1984.

PI Y Margall, F.: La reacción y la revolución, Madrid, 1854.

Pirala, A.: Historia de la guerra civil y de los partidos liberal y carlista, Madrid, 1868-69.

Posada Herrera: Lecciones de Administración, Madrid, 1843.

PugA, M. ${ }^{\mathrm{a}}$ T.: El matrimonio de Isabel II, 1964.

Rico y Амat: Diccionario de los políticos, ed.1976.

- Historia política y parlamentaria de España, Madrid, 1861.

RIVAS, N.: "Una crisis política en Barcelona", recogido en Políticos, gobernantes y otras figuras españolas, tomo l, pág. 205 y ss.

Rozalejo, Marqués de: Cheste o todo un siglo 1809-1906, Madrid, 1936.

SAGRA, R. de la: La reforma de la Constitución de 1837. Innecesaria, inoportuna y peligrosa, Madrid, 1844.

Sainz de Baranda, R.: Colección de leyes fundamentales (1808-1836), Zaragoza, 1957.

San Miguel, E.: Vida de D. Agustín Argüelles, 1851. 
SánChez AgeSta, L.: Soberanía nacional y Constitución interna, Granada, 1953.

- Historia del constitucionalismo español, ed.1964.

Sánchez Ferriz, R.: La Restauración y su Constitución política, Valencia, 1984, pág. 132.

Santillán, R.de: Memorias (1815-1856), Pamplona, 1968.

SeVILla ANDREs, D.: "El poder constituyente en España de 1800 a 1868», en Revista del Instituto de Ciencias Sociales, Barcelona, 1956.

- Constituciones y otras leyes y proyectos políticos de España, Madrid, 1962, 2 vols.

- El Senado de 1845, en homenaje a D. Nicolás Pérez Serrano.

- Historia política de España (1800-1967).

TAXonera, L. de: Gónzalez Bravo y su tiempo 1811-1871, Madrid, 1941.

TOMÁs VilLarRoYa, J.: "El proceso constitucional", en La era isabelina y el sexenio democrático, tomo XXXIV de la Historia de España de Menéndez Pidal dirigida por José Maria Jover Zamora, Madrid, 1981.

- El sistema político del Estatuto real (1834-1836), Madrid, 1968.

Tuñón dE LARA, M.: La España del siglo XIX, 1968. 